\title{
A Power Sharing Methodology Considering Wavelet Transform in a Residential Prosumer with a Hybrid Storage System
}

\author{
Metodología de distribución de la potencia en un sistema de almacenamiento \\ híbrido utilizando transformada wavelet en un consumidor residencial
}

\author{
V. Triviño-Castañeda ; A. Escobar-Mejía ; M. Holguín-Londoño iD
}

\begin{abstract}
Power systems have faced significant changes in recent years due to the integration of renewable energies in the power grid. Thanks to its multiple advantages, the so-called clean energies play an important role in the development of the electrical system, allowing the active participation of end users in energy markets. However, the intermittent nature of these sources has delayed their full integration into power systems; unless operated in conjunction with energy storage systems (e.g. batteries, ultracapacitors, etc.) to smooth out the generation and match the demand. This article presents a power sharing methodology for the exchange of energy between batteries and ultracapacitors in a photovoltaic installation. The case study comprises a hybrid energy storage system, on-site generation and a residential user, where both the load and generation profiles are analyzed using wavelet transform. The high- and lowfrequency components of both profiles are used to calculate the energy that is injected into the energy storage system. Results show that by separating the components of the signal in high and low frequencies it is possible to take advantage of the characteristics of each storage technology, extending its life cycle.
\end{abstract}

Index Terms-Battery; Hybrid Energy Storage System (HESS); Renewable energies; Ultracapacitors (UCs); Wavelet transform.

Resumen-Los sistemas de energía se han enfrentado a cambios importantes en los últimos años debido a la integración de las energías renovables en la red. Gracias a sus múltiples ventajas, las llamadas energías limpias juegan un papel importante en el desarrollo del sistema eléctrico, permitiendo la

This manuscript was sent on August 31, 2019 and accepted on March 09, 2020. This research project was financially supported by la Universidad Tecnólogica de Pereira, research project no. 6-19-3.

V. Triviño-Castañeda is with Engie Servicios Colombia, calle 16 no. $24^{a}$ 23, Palmira, Colombia, valentina.trivino@engie.com.

A. Escobar-Mejía is the Electrical Engineering Master's Program Director at la Universidad Tecnológica de Pereira, and is part of the Power Electronics research group (COL0025979), cra. 27 no. 10-02, Álamos, Pereira, Colombia, 660003, andreses1@utp.edu.co.

M. Holguín-Londoño is with la Universidad Tecnológica de Pereira, and is part of the Management of Electrical, Electronic and Automatic Systems research group (COL0056939), cra. 27 no. 10-02, Álamos, Pereira, Colombia, 660003, mau.hol@utp.edu.co participación activa de los usuarios en la generación de energía. Sin embargo, la naturaleza intermitente de estas fuentes ha retrasado su integración completa en la red; este inconveniente ha hecho necesaria la implementación sistemas de almacenamiento de energía (por ejemplo, baterías, ultracapacitores, etc.) para facilitar su integración al sistema eléctrico. Este artículo presenta una metodología para el intercambio de energía entre baterías y ultracapacitores en un sistema fotovoltaico con el fin de obtener un sistema híbrido de almacenamiento de energía para un caso de estudio: un sistema fotovoltaico instalado a nivel residencial.

Para este caso, los perfiles de carga y generación se analizan utilizando transformada wavelet para obtener los componentes de alta y baja frecuencia que se requieren para calcular la energía que se inyecta en el sistema de almacenamiento de energía. Los resultados muestran que al separar los componentes de la señal en alta y baja frecuencia es posible aprovechar las características de cada tecnología de almacenamiento alargando su ciclo de vida.

Palabras claves - Baterías, Energías Renovables; Sistema de almacenamiento híbrido de energía, Ultracapacitores (UCs); Transformada wavelet.

\section{INTRODUCTION}

$\mathrm{R}$ ENEWABLE energies have had a great attention in recent years, especially solar energy that has reached $227 \mathrm{GW}$ at the end of 2015 [1]. Combined, all clean sources supply approximately $23.7 \%$ of the world's electricity demand [2]. Germany is the leader in photovoltaic production followed by China, Japan, Italy and the United States. The increase in generation is mainly due to government's policies -established in each country- to reduce global contamination. In Colombia bill number 1715 promotes the development and use of nonconventional sources of energy -mainly renewables- in the local power system. For this reason, in 2015 the installed capacity increased from $11.6 \mathrm{GW}$ to approximate $12 \mathrm{GW}$ [3]. Under this scenario is expected to have an increase of about 88 $\mathrm{kW}$ in the next two years, as shown in Table I.

The largest solar project in Colombia will be located in Yumbo (Valle del Cauca), with 35,000 panels that will prevent the emission of about 6,600 tons of $\mathrm{CO}_{2}$ per year. The solar 
facility is expected to be completed at the end of 2018 and will generate approximately $16 \mathrm{GWh}$ per year, equivalent to the monthly energy consumption of 8,000 homes. The high penetration levels of renewables into the electric power grid, causes several issues due to the fluctuating nature of the primary source, which could make the energy supply unreliable [1].

TABLE I

ELECTRICAL GENERATION PROJECTS IN COLOMBIA TO THE YEAR 2017 [3]

\begin{tabular}{ccc}
\hline \hline ESTATUS & $\begin{array}{c}\text { CAPACITY } \\
(\mathbf{k W})\end{array}$ & $\begin{array}{c}\text { ENERGY } \\
(\mathbf{k W h} / \mathbf{m o n t h})\end{array}$ \\
\hline Operating & $5,653.70$ & $15,231.80$ \\
Finalized & 133.44 & 15,239 \\
Ongoing & 39.92 & $4,246.90$ \\
Under construction & 72.00 & 10.34 \\
In planning & 87,709 & $2,812.81$ \\
TOTAL & $93,608.06$ & $2,847,536.50$
\end{tabular}

Furthermore, the mismatch between the photovoltaic generation curve and the load profile, cause power unbalances that demand the implementation of energy storage systems (ESS) or the introduction of additional power supplies [4]. To address this problem, several approaches have been proposed: new wind and solar forecasting tools, demand side control, and fast-start units [5]. Within these solutions, the ESS is a promising method thanks to its fast response and control flexibility. In the framework of renewable energies, the ESS storage the surplus energy delivered by the renewable source to provide energy to loads when, for instance, the solar radiation is low or when the load requirements are not meet [6].

The ESS is designed using different technologies or even combining different types of storage systems in order to maximize the benefits. Several aspects such as power and energy density, nominal power, time of discharge, storage duration, efficiency, duty cycle, and lifetime, are considered in order to select the ESS for a particular application. In the case of photovoltaic systems, batteries and Ultra-Capacitors (UCs) have been widely accepted since they are a cost-effective solution when compared with similar approaches. The batteries are profitable because they store a good amount of energy; however, it is not easy for them to recover from fast power fluctuations because they do not supply large amounts of energy in a short time span without affecting their lifetime [6]. On the other hand, the UC have high power density, which facilitates fast charge and discharge during several cycles without compromising their efficiency [7]. Therefore, it is convenient to combine these two technologies to obtain complementary benefits and overcome the disadvantages of each type of storage.

To this end, it is necessary to separate the frequency components, so the UCs provide (or storage) the high frequency components when required. On the other hand, batteries take the low frequency components, which allow them to deliver energy for long periods.
Wavelet analysis is a signal-processing tool that is effective for the analysis of non-stationary signals. It is widely used to perform transient analyzes of power system and to determine the quality of the power. The wavelet transform has multiple applications in distributed generation: in island operation it is used to extract information from generators to detect certain frequency bands [8], it is also used to analyze the behavior of transient signals when there is a disturbance in the distribution system [9]. The wavelet limit coefficients provide real-time detection of "failure's start-time" to reduce the operating time of relays and minimize the harmful effects of faults [10]. In [11] the wavelet transform is used to size the Hybrid Energy Storage System (HESS) required to mitigate shot-term and long-term fluctuations in a wind farm. Similarly, in [12] a HESS is used to stabilize a wind generation system by means of the wavelet transform in conjunction with a sliding mode controller; however, its analysis is not straightforward since it is necessary to add a fuzzy controller to eliminate the vibration of the sliding modes.

This paper presents a power sharing methodology for a photovoltaic system with a HESS (battery and a UC banks) of a residential prosumer (consumes and produces electricity). In section two, the description of the HESS and its configuration is provided. Section three presents the fundamentals of the wavelet transform used in this document. In section four, the case study is described. A power sharing method is described in section five to maintain the voltage at the desired levels through the energy exchange between batteries and UCs. Results and analyses from time-domain simulations are presented in section six. Finally, conclusions are provided in section seven.

\section{HESS FOR PHOTOVOLTAIC SYSTEMS}

Energy storage systems are fundamental to ensure high levels of energy quality and an adequate energy management in renewable energy systems. An ideal storage technology offers fast access to energy when needed, provides a good amount of power, has a long lifespan and is available at a competitive cost. However, currently there is no ESS technology that can fulfill all these desirable characteristics simultaneously. There are different storage technologies that have different properties, including UCs, flywheels and superconducting magnetic energy storage (SMES). They offer quick responses to energy requirements, have a very high life cycle, considering the loading and unloading. For these reasons, these technologies are considered good components to support energy in power systems; however, the cost per-unit of stored energy is very high. On the other hand, batteries are considered an adequate cost-effective solution, mainly limited by the short-life cycle due to the loading and unloading processes to which they are frequently subjected [13].

The fluctuating and unpredictable nature of solar energy necessarily involves storage technologies used in complementary mode to effectively smooth out fluctuations. The combination of two types of storage technologies allows to use the advantages of each one without exceeding the limits in loading or unloading, and extending their lifespan [14]. 
Ultra-capacitors can deliver high energy peaks, furthermore they can be charged or discharged several times without having consequences on efficiency, however, their storage capacity is limited [11]. On the other hand, batteries are able to store large amounts of energy (high energy density) and their charge/discharge process is slow. Combining both UCs and a battery bank is possible to minimize long-term and short-term fluctuations [4], [6], [11].

\section{WAVELET TRANSFORM}

A wavelet is considered a waveform with limited time duration and average value of zero, which is implemented to breaking up of a signal into shifted and scaled versions of the original (mother) wavelet. It is specially used to analyze nonperiodic and non-stationary signals that present suddenly changes and fast transients [15].

The wavelet maps the signal into a time-scale representation where the temporal aspect of the signals is preserved. The difference with other time-frequency transforms is that the wavelet transform provides multiresolution analysis with dilated windows. Here the analysis of the high-order-range frequencies is performed using narrow windows, whereas loworder frequencies use wide windows. The basic functions of the wavelet transform are generated from a basic wavelet function, by means of translations and expansions [16]. The wavelet transform of a function $f(t)$ is the decomposition of $f(t)$ in a set of functions $\Psi_{s, t}(t)$ that forms a base called the "wavelets". Mathematically the wavelet transform is defined as follows:

$$
W_{f}(s, \tau)=\int f(t) \Psi_{s, \tau}^{*}(t) d t
$$

The wavelets are generated from the translation and change of scale of a same wavelet function $\Psi(t)$, called the "mother wavelet", and is defined as in (2).

$$
\Psi_{s, \tau}(t)=\frac{1}{\sqrt{s}} \Psi\left(\frac{t-\tau}{s}\right)
$$

The wavelets $\Psi_{s, t}(t)$ generated from the same mother wavelet function $\Psi(t)$ have different scale $(s)$ and location $(\tau)$, but they all have the same form. Scale factors are always used when $s>0$, and wavelets are dilated and contracted when $s>1$ and when $s<1$ respectively. Thus, changing the value of $s$ covers different frequency ranges. Large values of $s$ correspond to lower range frequencies, or a large scale of $\Psi_{s, t}(t)$. Small values of $s$ correspond to frequencies with lower rank or a very small scale of $\Psi_{s, t}(t)$ [16]. In this sense, for a particular signal, the "approximations" are defined for high-scale and low-frequency components, and "details" as the components for low-scale and high-frequency [15]. The filtering process, which produces the DWT coefficients, is shown in fig. 1.

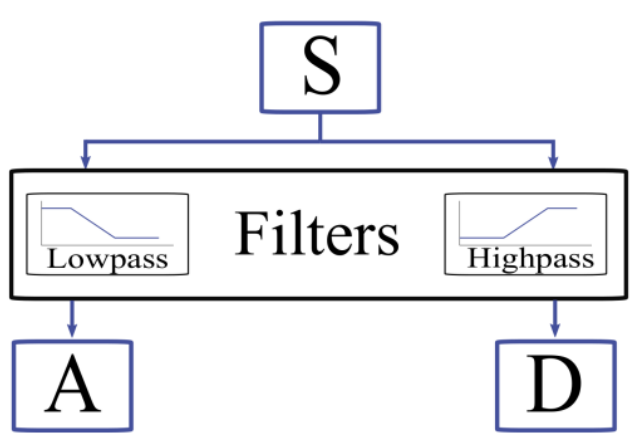

Fig. 1. Filtering Process with one level [15].

\section{CASE STUdy DESCRIPTION}

The single-phase residential prosumer shown in fig. 2 is studied. A photovoltaic array with a peak capacity of $4 \mathrm{kWp}$ is considered to locally generate power. The prosumer uses a HESS, comprising batteries and UCs connected in parallel to mitigate long-term fluctuations and short-term fluctuations respectively, and to store the surplus energy. Both ESS are connected to a $48-\mathrm{V}$ dc bus through dc-dc bidirectional converters. The photovoltaic array is also connected to the dcbus using a unidirectional dc-dc converter, whereas two dc-ac converters are used to interface both the residential user and the local dc-bus with the utility. It is worth noting that in this case, no energy is feed back into the grid and the dynamic of the converters are not considered.

The typical daily load profile $\left(P_{\text {load }}\right)$ from the residential user and the power generated by the photovoltaic array $\left(P_{P V}\right)$ are depicted in fig. 3 .

Both curves have a minute sample time (1440 samples percurve) and are real measurements taken from a photovoltaic system located in the main campus of la Universidad Tecnológica de Pereira and a local customer on a low voltage feeder [17]. Table II lists the characteristics of the case study, which includes the photovoltaic array and the HESS [18].

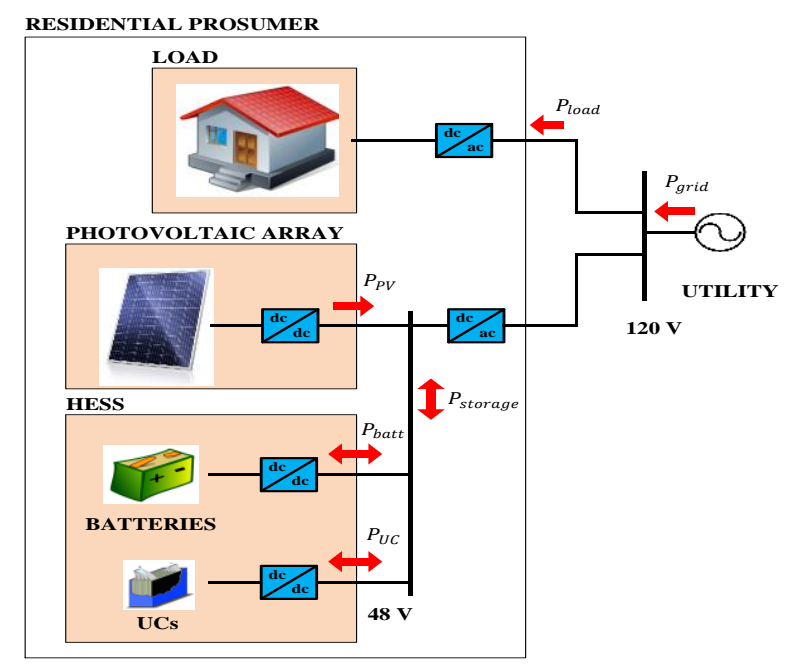

Fig. 2. Case study description. 


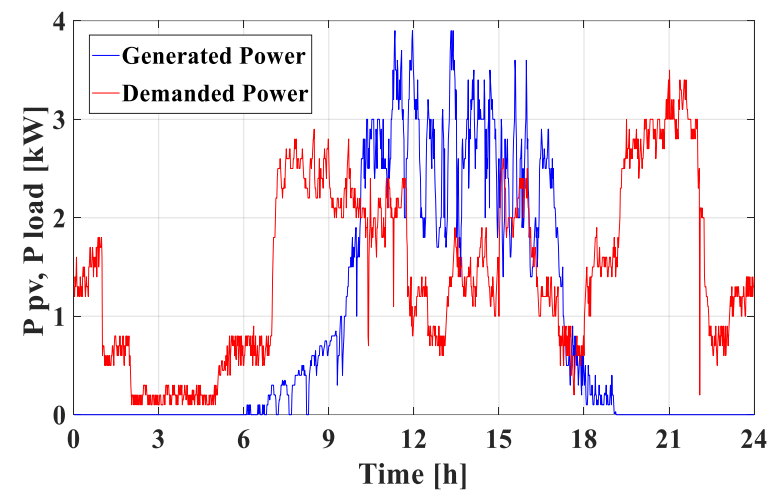

Fig. 3. Generation profile from the photovoltaic array (blue) and load profile (red).

TABLE II.

CASE StUdy Main PARAMETERS. SOURCE: AUtHORS' OWN WORK

\begin{tabular}{cc}
\hline \hline PARAMETER & VALUE \\
Photovoltaic Array & \\
Peak power & $4 \mathrm{kWp}$ \\
Batteries & \\
Bank capacity & $100 \mathrm{Ah}$ \\
Initial State-of-charge & $30 \%$ \\
Output nominal voltage & $48 \mathrm{~V}$ \\
Ultracapacitors & \\
Bank capacity & $600 \mathrm{~F}$ \\
Output nominal voltage & $48 \mathrm{~V}$ \\
\hline \hline
\end{tabular}

\section{Power Sharing Methodology}

As mentioned earlier, batteries are ideal to provide large amounts of energy during long periods, however due to their slow response, they are combined with UCs, which have fast response to supply or absorb power. In a hybrid system is necessary to separate the low (long-term) and the high (shortterm) power components, to be stored in the battery and the UC respectively.

The resulting power in (3) indicates the required/stored energy from/into the HESS -or even the utility if necessaryto meet the load requirements. Now, by separating this signal and defining the high and low frequencies, it is possible to find the components through the wavelet analysis.

$$
P_{\text {storage }}=P_{\text {load }}-P_{P V}
$$

To this end, the components are used to size the required ESS and evaluate its state of charge, voltage and current. To get the high and low frequency components of the power signal $P_{\text {storage }}$, a wavelet-based algorithm is created using Matlab to apply the wavelet transforms, and identify the coefficients for slow and fast transients of $P_{\text {storage }}$. These coefficients are shown in fig. 4(a) and 4(b) respectively.

Fig. 5 (a) indicates the required $P_{\text {storage }}$ to meet the load requirements. If $P_{\text {storage }}>0$ then the HESS is delivering energy to the load, on the contrary, $P_{\text {storage }} \leq$, the storage system is being charged. As a result of the wavelet analysis, the power provided by the batteries $P_{\text {batt }}$ (low frequencies) is presented in fig. 5 (b). As mentioned before, positive values indicate power delivered by the batteries and the negative part indicates their charge.

The power used to charge the HESS from the photovoltaic array is shown in fig. 5 (c).

Within the proposed analysis for the distribution of energy using these technologies, the state of charge (SOC) and voltage of each device is considered to ensure the life for the battery [19]. In this case, a SOC of $0 \%$ indicates that each device is fully discharged and a SOC of $100 \%$ indicates that is fully charged. It has been prove that the life cycle is affected if the limits of the SOC are not kept. For the batteries, the upper limit is set to $100 \%$ and the lower limit is set to $20 \%$. This helps to avoid overloads and discharges that may cause severe damage [6].

On the other hand, the state of charge of the UCs can be expressed as in (4), where $E$ is the energy stored at a particular moment, and $E_{\min }$ and $E_{\max }$ are the minimum and maximum energy respectively. To this end, it is possible to find the energy in the UC as in (5), where $V$ is the voltage in the UC at certain instant and $C$ is its capacity in farads.

$$
\begin{gathered}
S O C_{S C}=\frac{E-E_{\min }}{E_{\max }-E_{\min }} \\
E_{S C}=\frac{1}{2} C V^{2}
\end{gathered}
$$

In this paper, a minimum energy of $49 \%$ of the total energy is preserved in order to maintain a maximum voltage of $70 \%$ of the nominal voltage, as indicated in (6). In this sense, when the voltage across the UC is $70 \%$ of its nominal voltage, the SOC is $0 \%$, which means that it is fully discharged. As mentioned above it is necessary to keep the SOC within a limit to guarantee the operation of the UC. In this case, a SOC of $70 \%$ has been established to obtain the value of the reference voltage.

Solving (4) and (5) is possible to get (6), and as a result, the reference voltage is $44.18 \mathrm{~V}$.

$$
E_{\text {min }}=\frac{1}{2} C\left(0.7 V_{\text {nom }}\right)^{2}=0.49 E_{\max }
$$

To achieve a correct management of the energy between both technologies, a PI controller is implemented. This controller uses the voltage measured in the UCs and the reference in order to generate the current that charges or discharges the UC depending on the power flow [20]. 


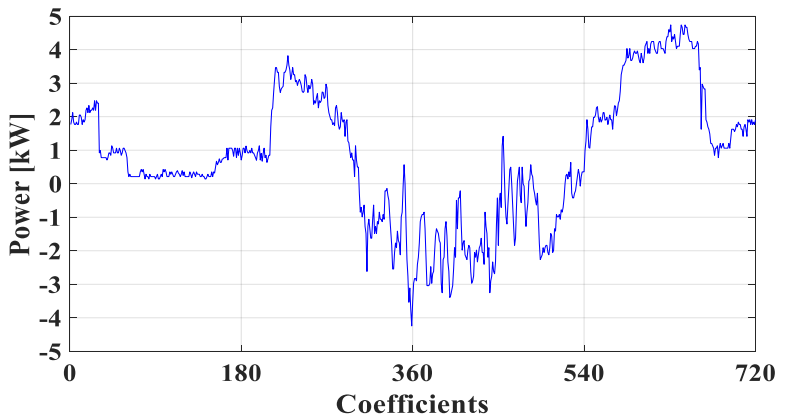

(a)

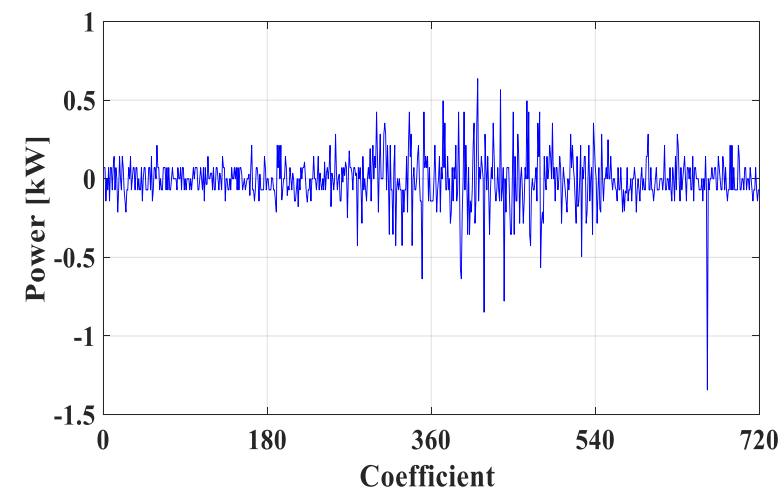

(b)

Fig. 4. Wavelet coefficients for low (a) and high frequencies (b).
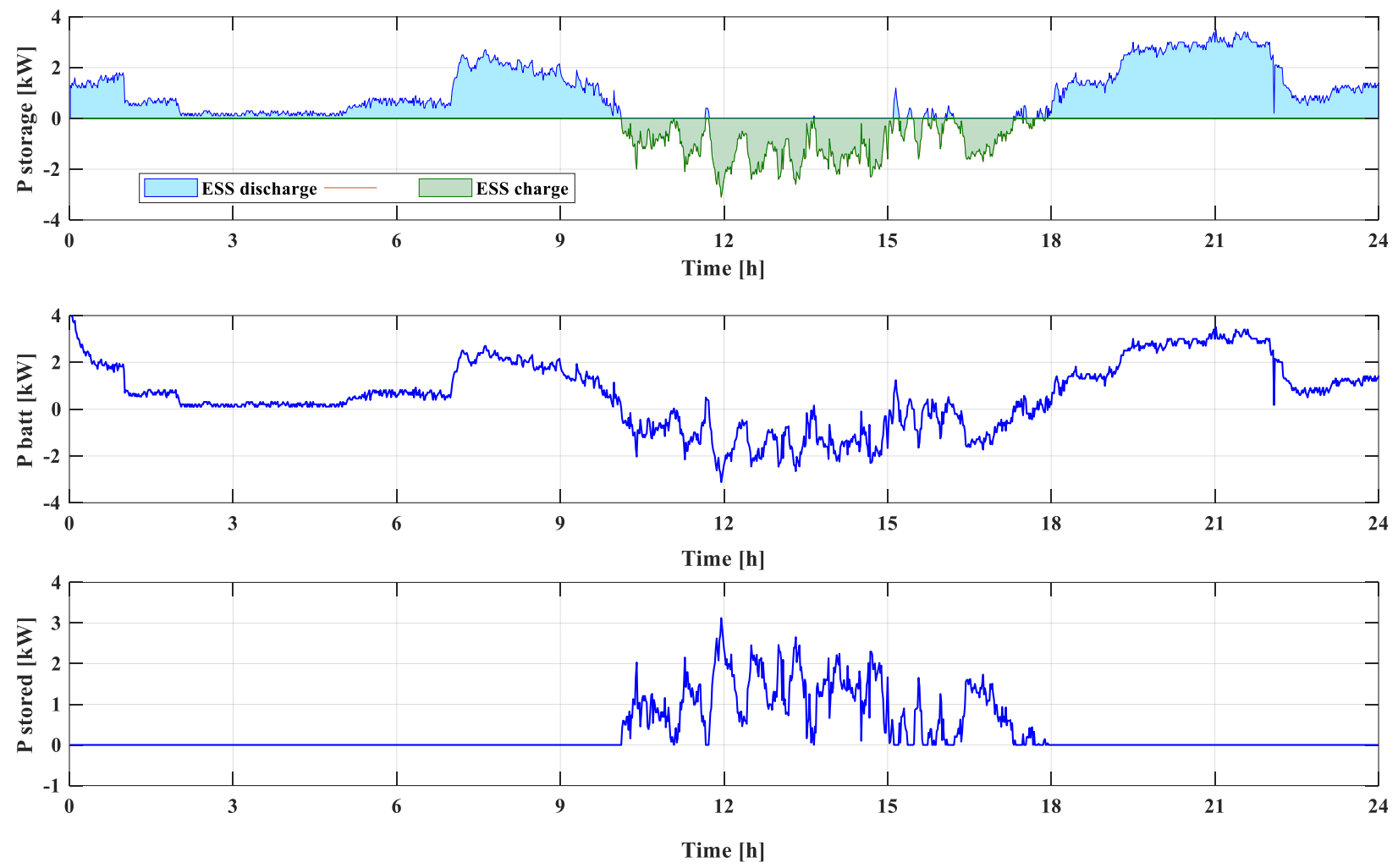

Fig. 5. Power in the HESS to match the load requirements (a), power in the HESS considering the long-term power components (b) and power delivered by the photovoltaic array to charge the HESS.

\section{RESULTS AND ANALYSIS}

The proposed power sharing method has been validated in the system illustrated in Fig. 2, which considers a HESS. The batteries have a SOC of $44.4 \%$ and a nominal voltage of $48 \mathrm{~V}$. For the UC, the voltage never exceeds $44.2 \mathrm{~V}$, which is the limit to keep $70 \%$ of its SOC.

As shown in fig. 6(a) the PI controller regulates the SOC of the UCs, causing small changes around the desired value, while the UC voltage remains at the reference value as indicated in Fig. 6(b). In fig. 6(c) the positive slope indicates that the battery is being charged with the energy coming from the photovoltaic system. The negative slope indicates the discharge of the battery to meet the load profile shown in Fig. 3. This shows the power exchange between the batteries and the UC by keeping the voltage at desired levels in the UC. Under this 24-hours scenario, no energy is required from the grid since the SOC of the batteries never go below the defined lower limit (20\%).

The current flowing through the batteries in a 24-hours period is shown in Fig. 7. It can be seen that the current changes in direction depending if the battery is either charge or discharge. 


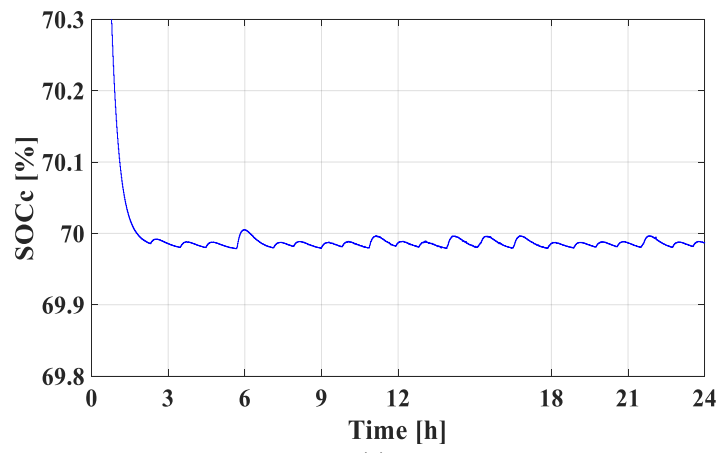

(a)

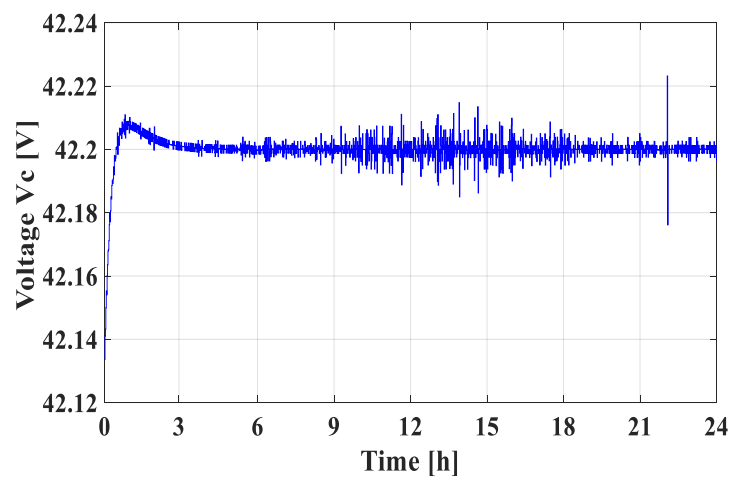

(b)

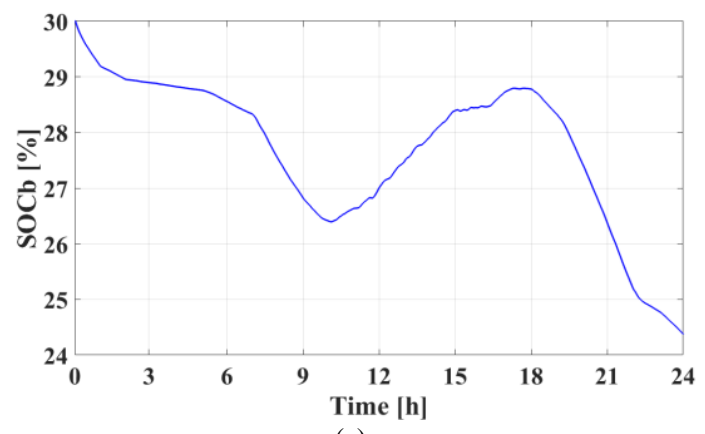

(c)

Fig. 6. SOC (a) and voltage (b) of the UCs, and batteries SOC (c).

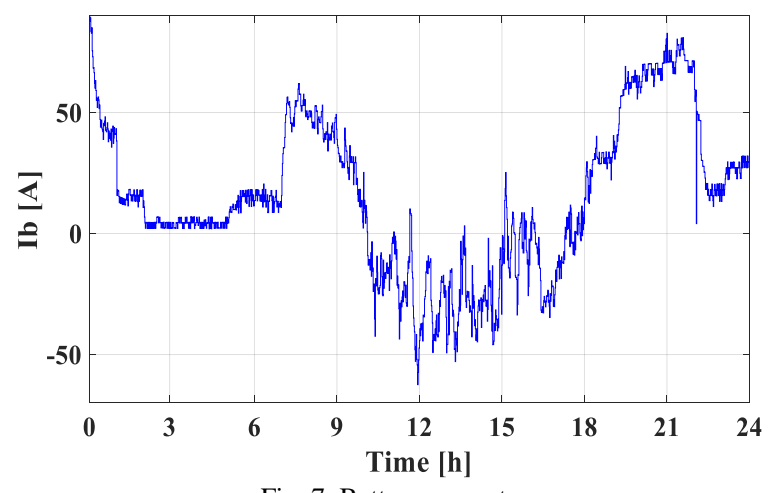

Fig. 7. Battery current.

\section{CONCLUSION}

This paper presented an energy control strategy for a residential prosumer that has a distributed generation system in conjunction with photovoltaic generation. The system included a HESS, which comprised a set of batteries and UCs.

The proposed strategy allowed the energy exchange between the two storage technologies to extend the life of both by establishing voltage and SOC limits. The analysis showed how both the power sharing methodology and the control scheme, helped to keep the SOC for the HESS between their limits.

As a future work, economic aspects, cost of electricity, capital cost, etc., will be considered in further investigations.

\section{REFERENCES}

[1] World energy council, "Solar", 2016. [Online]. Available: https://www.worldenergy.org/wp-

content/uploads/2017/03/WEResources_Solar_2016.pdf. [Accessed on: Aug. 28, 2018].

[2] REN21 Renewable Energy Policy Network for the 21st Century, "Energías Renovables 2016, reporte de la situación mundial", 2016. [Online]. Available: http://www.ren21.net/wp-content/uploads/2016 /06/GSR_2016_KeyFindings_SPANISH.pdf. [Accessed on: Aug. 26, 2018].

[3] J. Gómez-Ramírez, J.D. Murcia-Murcia, I. Cabeza-Rojas, "Energía solar fotovoltaica en Colombia: Potenciales, antecedentes y $\begin{array}{lll}\text { perspectivas", } 2017 . & \text { [Online]. }\end{array}$ https://repository.usta.edu.co/bitstream/handle/11634/10312/G\%C3\% B3mez2018.pdf?sequence=1\&isAllowed=y. [Accessed on: Dec. 05, 2018].

[4] Y. Wang, X. Lin and M. Pedram, "Adaptive Control for Energy Storage Systems in Households with Photovoltaic Modules," in IEEE Transactions on Smart Grid, vol. 5, no. 2, pp. 992-1001, March 2014. DOI: 10.1109/TSG.2013.2292518

[5] Y.V. Makarov, P. Du, M.C.W. Kintner-Meyer, C. Jin and H.F. Illian, "Sizing Energy Storage to Accommodate High Penetration of Variable Energy Resources," in IEEE Transactions on Sustainable Energy, vol. 3, no. 1, pp. 34-40, January, 2012. DOI: $10.1109 /$ TSTE.2011.2164101

[6] M. Ruiz-Cortés, E. Romero-Cadaval, C. Roncero-Clemente, F. Barrero-González and E. González-Romera, "Energy management strategy to coordinate batteries and ultracapacitors of a hybrid energy storage system in a residential prosumer installation," in Proceedings of the 2017 International Young Engineers Forum (YEF-ECE), Almada, 2017, pp. 30-35. DOI: 10.1109/YEF-ECE.2017.7935636

[7] Y. Liu, W. Du, L. Xiao, H. Wang, S. Bu and J. Cao, "Sizing a Hybrid Energy Storage System for Maintaining Power Balance of an Isolated System With High Penetration of Wind Generation," in IEEE Transactions on Power Systems, vol. 31, no. 4, pp. 3267-3275, July, 2016. DOI: 10.1109/TPWRS.2015.2482983

[8] W. G. Morsi, C. P. Diduch and L. Chang, "A new islanding detection approach using wavelet packet transform for wind-based distributed generation," in Proceedings of the 2nd International Symposium on Power Electronics for Distributed Generation Systems, Hefei, 2010, pp. 495-500. DOI: 10.1109/PEDG.2010.5545860

[9] S. Ananwattanaporn and A. Ngaopitakkul, "Study of Multidistributed Generation Behavior when Fault Occurrence in Distribution System Using Wavelet Transform," in Proceedings of the 2016 Joint 8th International Conference on Soft Computing and Intelligent Systems (SCIS) and 17th International Symposium on Advanced Intelligent Systems (ISIS), Sapporo, 2016, pp. 148-153. DOI: 10.1109/SCIS-ISIS.2016.0042

[10] F.B. Costa, A. Monti and S.C. Paiva, "Overcurrent Protection in Distribution Systems With Distributed Generation Based on the RealTime Boundary Wavelet Transform," in IEEE Transactions on Power Delivery, vol. 32, no. 1, pp. 462-473, February, 2017. DOI: $10.1109 /$ tpwrd.2015.2509460

[11] Q. Jiang and H. Hong, "Wavelet-Based Capacity Configuration and Coordinated Control of Hybrid Energy Storage System for Smoothing Out Wind Power Fluctuations," in IEEE Transactions on Power Systems, vol. 28, no. 2, pp. 1363-1372, May, 2013. DOI: 10.1109/TPWRS.2012.2212252

[12] J. Xiao, L. Bai, F. Li, H. Liang and C. Wang, "Sizing of Energy Storage and Diesel Generators in an Isolated Microgrid Using Discrete Fourier Transform (DFT)," in IEEE Transactions on Sustainable Energy, vol. 5, no. 3, pp. 907-916, July, 2014. DOI: 10.1109/TSTE.2014.2312328

[13] Z. Song, J. Hou, H. Hofmann, X. Lin and J. Sun, "Parameter Identification and Maximum Power Estimation of 
Battery/Supercapacitor Hybrid Energy Storage System based on Cramer-Rao Bound Analysis," in IEEE Transactions on Power Electronics, in press, pp. 1-14. DOI: 10.1109/TPEL.2018.2859317

[14] L.F. Bedoya, "Efectos del desarrollo tecnológico de las baterías en el Sistema Interconectado Nacional de Colombia," Trabajo de Grado, Facultad de Minas, Universidad Nacional de Colombia sede Medellín, 2017. [Online]. Available: http://bdigital.unal.edu.co/59228/1/1128436130.2017.pdf. [Accessed on: Dec. 05, 2018].

[15] M. Misiti, Y. Misiti, G. Oppenheim, J.M. Poggi, "Wavelet Toolboox User's Guide”, 2015, Accessed on: Dec. 05, 2018. [online]. Available:

http://profesores.elo.utfsm.cl/ mzanartu/IPD414/Docs/wavelet_ug.pd $\mathrm{f}$

[16] Introducción a la transformada wavelet, "Descomposición de señales", 2006. [Online]. Available:

http://www.exa.unicen.edu.ar/escuelapav/cursos/wavelets/apunte.pdf. [Accessed on: Jul. 04, 2018].

[17] REDH, "Datos de Radiación Red Hidroclimática de Risaralda,"2019. [Online]. Available: http://redhidro.org/home/. [Accessed on: Dec. 05, 2018].

[18] Victron Energy. "Batería de Plomo-carbono," [Online]. Available: https://www.victronenergy.com.es/upload/documents/DatasheetLead-carbon-battery-ES.pdf. [Accessed on: Dec. 05, 2018].

[19] O. Palizban, K. Kauhaniemi, "Power Sharing for Distributed Energy Storage Systems in AC Microgrid: Based on State-of-Charge," in Proceedings of the IEEE PES Asia-Pacific Power and Energy Conference (APEC), 2015, pp. 1-5. DOI: 10.1109/APPEEC.2015.7381023

[20] D.L. Cheng, M.G. Wismer, "Active Control of Power Sharing in a Battery/Ultracapacitor Hybrid Source," in Proceedings of the 2nd IEEE Conference on industrial Electronics and Applications, 2007, pp. 2913-2918, 2007. DOI: 10.1109/ICIEA.2007.4318947.

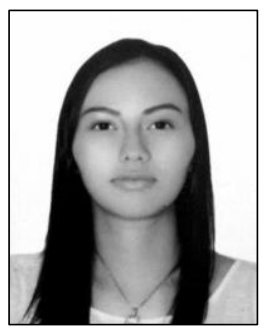

Valentina Triviño Castañeda was born in Bello, Antioquia in 1995. She received her bachelor degree in Electrical Engineer at la Universidad Tecnológica de Pereira in August 2017. She began hers master's degree in electrical engineering the same year at the same university, where she worked as a lectures in 2028. In 2019 she started working on a French company called ENGIE as a design engineer, where she is currently working. Her research areas are energy storage systems, renewable resources, signal processing and neural networks.

ORCID: https://orcid.org/0000-0003-3277-2470.

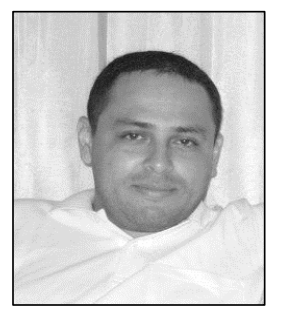

Andres Escobar Mejia (S'09- M'15) was born in Pereira in 1977. He received the B.E. degree and the M.Sc. degree both in electrical engineering from la Universidad Tecnológica de Pereira, Risaralda, Colombia, in 2002 and 2004, respectively. He got his $\mathrm{Ph} . \mathrm{D}$. degree at the University of Arkansas, Fayetteville, AR, USA, under Dr. Juan C. Balda advisory in 2014.

In 2007, he joined the Department of Electrical Engineering, at La Universidad Tecnológica de Pereira, as a lecturer, and became an associate Professor in 2014. For the past seven years, he has been working on the area of power electronics with emphasis on matrix converters, dc-dc isolated converters and the integration of renewables with the power grid,
Modular Multilevel Converters and Solid State Transformers. $\mathrm{He}$ is also working on electrical machines and drives, active filters, flexible ac transmission systems, high-voltage dc, and power quality. Currently he is the director of the master program in Electrical Engineering of la Universidad Tecnológica de Pereira.

ORCID: https://orcid.org/0000-0002-0061-4278.

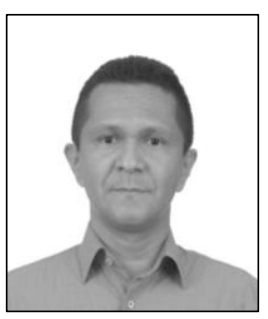

Mauricio Holguín Londoño was born in Pereira, Risaralda, Colombia in 1974. He received the B.S. and M.S. degrees in electrical engineering from la Universidad Tecnológica de Pereira, Risaralda, in 2009 and the Ph.D. in engineering, from the Universidad Tecnológica de Pereira, Risaralda, in 2018.

From 2006 to 2008, he was a research Assistant with the Automatic research group in la Universidad Tecnológica de Pereira. From 2009 to 2014, he was assistant Professor with the electrical engineering program. Since 2014 he has been associate professor with the Faculty of Engineering at the same university. He is the author of more than three books, 30 conference papers and several journals. He has also develop 25 software related products. Since 2010 he has been researcher and director of the research group in Management of Electrical, Electronic and Automatic Systems. His research interests include applications in industrial instrumentation, automatic control, quality control, asset management of electrical systems and autonomous maintenance, inspection, reliability and quality control systems with non-invasive techniques. Dr. Hoguín-Londoño was awarded as a distinguished student of la Universidad Tecnológica de Pereira in 1997.

ORCID: https://orcid.org/0000-0001-6284-3327. 